\title{
Challenges in Communication with Nursing and Midwifery Council of Nigeria (NMCN)
}

\author{
${ }^{1}$ Princewill Aghedo. \\ London Professional Training Centre, \\ Lagos state.
}

${ }^{2}$ Isaiah Dada Owoeye.

Corresponding author

Department of Nursing science,

College of Medicine and Health Science

Afe Babalola University, Ado-Ekiti, Ekiti state.

\author{
${ }^{3}$ Moses Adeyemo \\ Nurses and Politics, Nigeria
}

\author{
${ }^{4}$ Victor Bayem Nwachukwu \\ University of Benin Teaching \\ Hospital, \\ Benin-City, Edo state.
}

\author{
${ }^{5}$ Oluwatomisin Ogidan \\ Department of Nursing, \\ Obafemi Awolowo University, \\ Ile-Ife, Osun state.
}

\begin{abstract}
Communication is an important aspect of organisation's relationship in service to the public. The study investigates nurses' opinion on 'Challenges in communicating with Nursing and Midwifery Council of Nigeria (NMCN)'. This is a descriptive web-based study with 896 participants. Data analysis was done using Google form. The result showed that $91.1 \%$ majority of the respondents were Registered/Graduate nurses. Majority $\mathbf{7 4 . 1 \%}$ have tried to reach out to Nursing and Midwifery Council of Nigeria (NMCN) through email, phone calls, text messages, Letters etc. $39.2 \%$ of those who reached out by email never got any reply. The participants suggested a better customer service, embracement of online availability and prompt responses to the received messages by Nursing and Midwifery Council of Nigeria (NMCN). The study recommends that an active online availability by NMCN to improve communication.
\end{abstract}

Keywords:- Challenges, NMCN, Communication, Nursing.

\section{INTRODUCTION}

Communication is an integral part of day-to-day activities. It is used to convey feeling, opinion and other relevant matters from one person to another and or across organisation. Effective communication in an organisation increases job output and makes the organisation to succeed [1]. The organisation that render services to the public has the onus of keeping in tune with the people it serves through continual and uninterrupted communication. Communication is stated as one of the core values of a nursing regulatory board [2]. An appraisal of organisation's standard is measured by the function of effective dissemination of information; therefore management team has the responsibilities of ensuring their employees are up to task in meeting up with the goal[3].

In the present age, there is a paradigm shift in the communication network and this is brought about by the advent of Information Communication Technology (ICT) which is the hallmark of communication means in the $21^{\text {st }}$ century. The key to up-to-date performance in the growing competitive world is the ability of the professionals to utilize Information Communication Technology to aid service delivery [4]. In the world, there is a documented increase in the statistics of ICT users from one billion to three billion within the space of a decade, which is 2005 and 2015 respectively. ICT is now a key to human activities and a life wire of any organisation [5]. The increase in the need to be more efficient on the job, in order to secure the means of livelihood, has placed a top priority on the need to be Information Technology Communication compliant by individuals at work [6].

In comparison, the present means of communication is faster than the former means. In other to keep abreast with the current trends in communication, NMCN has also improved her services to be data driven with ICT compliance through the introduction of online registration for registration, licensing etc. According to RobinsonBassey \& Edet [4], Nursing and Midwifery Council of Nigeria should reflect their service package to be in line with the use of modern technology as nursing service in this present dispensation needs the combination of nursing science with Information science and Computer science. The directive on these services, registration, licensing etc, has been communicated to nurses in Nigeria [7]. The Council had earlier mandated among many other things that the benchmark for the training of students in Schools of Nursing and Department of Nursing across Nigeria are internet facilities and appropriate number of computers [4].

Organisational appraisal for effectiveness is based on her ability to disseminate information or communicate thoughts to people and to receiving a due response that is aimed at meeting the organisational aims and objectives [3]. Although the Council has upgraded its communication link through the use ICT, however, there are still gaps as many nurses still complain of a delayed service in certain duties that NMCN renders to them. According to Geraets [8], challenges with communication could increase the waiting time and in turn increases the resolution timeframe, therefore staff training and orientation are the obvious means to implementing the new communication strategies. The difficulty associated with change in system of the nursing board has caused nurses to be worried about their status and credentialing as a registered nurse [9]. 
ISSN No:-2456-2165

Some had put a call through to NMCN, travelled miles to get the issue solved to time or resolved to fate on the expected services. It is based on this premise that the study was conceived to investigate the challenges in Communicating with Nursing and Midwifery Council of Nigeria (NMCN).

\section{Objectives of Study}

The broad objective of the study is to investigate challenges in Communicating with NMCN. The specific objectives for the study are;

- To assess nurses' attempt to communicate with NMCN.

- To determine the time-frame in $\mathrm{NMCN}$ reply of the messages.

- To assess nurses' access to NMCN offices

\section{METHOD AND MATERIAL}

A descriptive survey was used to access challenges in Communicating with NMCN. The study setting was online. The population for the study is 250,000 nurses in Nigeria. At $99 \%$ Confidence interval and 5\% margin of error, a sample size of 667 was computed using the Creative Research Systems Survey software of the Sample size calculator [10]. 20\% non-response/attrition rate was computed to be 730 sample sizes. Since restriction is not controlled online, the response rate makes up to 896, thereby making the Data Generating Sample to be 896 . The instrument used was a self-constructed instrument designed to elicit responses in line with the study. The instrument was created in a Google form and it contains 8 test items to make it time friendly for the respondents. Data collection spanned over 8 weeks. Data analysis was through Google automatic analysis. Consent was through implied filling of the questionnaire with willingness.

\section{RESULTS}

Majority $91.1 \%$ of the respondents are Registered/Graduate nurses. $74.1 \%$ of the respondents had tried to reach out to NMCN through email, phone calls, text messages, Letters and social media of which $39.2 \%$ never got any reply when they reached out to $\mathrm{NMCN}$ via email. Majority $78 \%$ stated that it is not convenient to travel from their location to any of the NMCN offices and $65.8 \%$ know that NMCN have zonal offices across the Six (6) geopolitical zones in Nigeria.

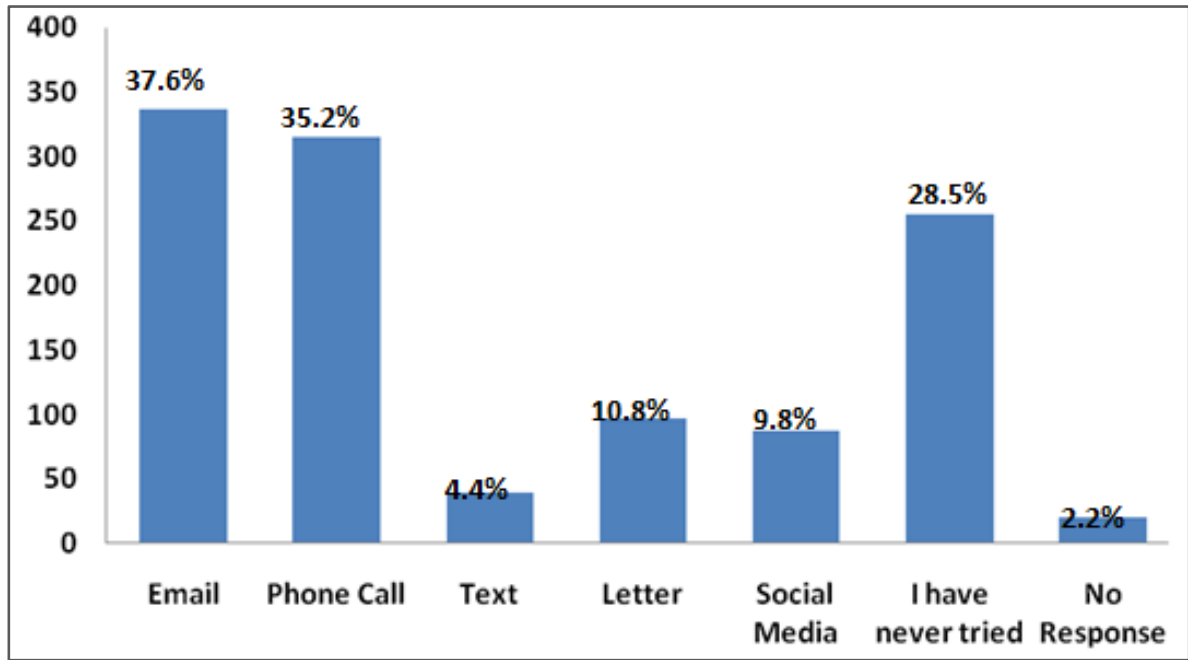

Fig 1:- Attempt to reach out to NMCN

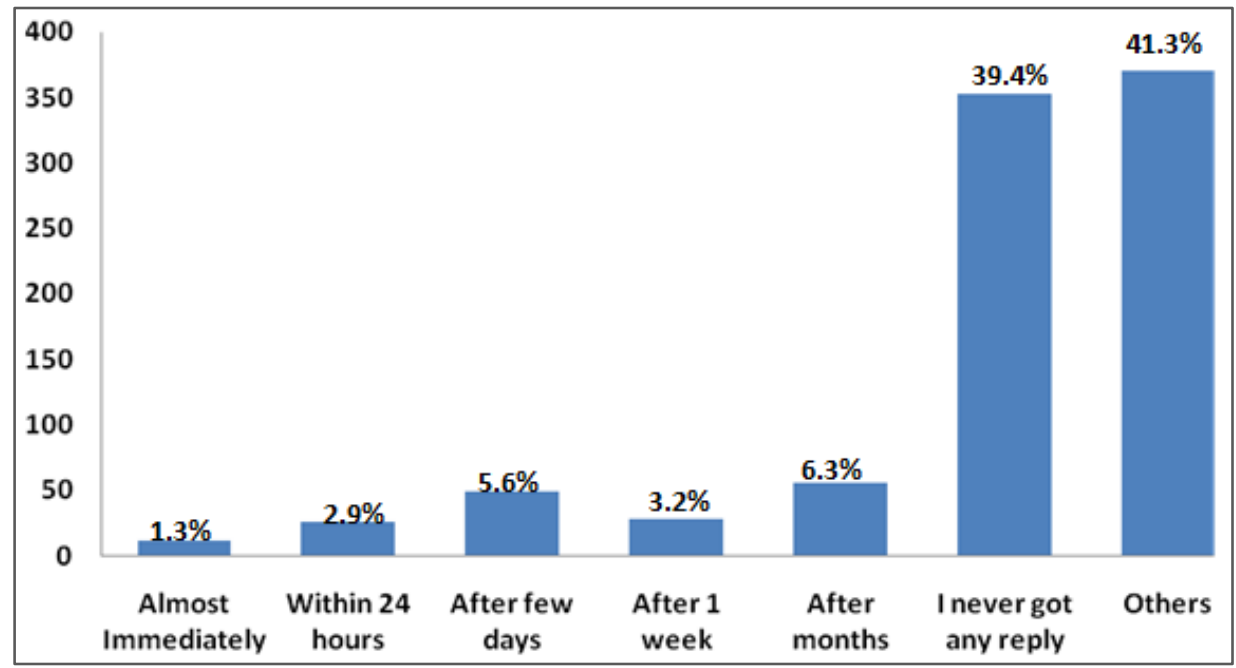

Fig 2:- Time frame in NMCN reply to messages. 
ISSN No:-2456-2165

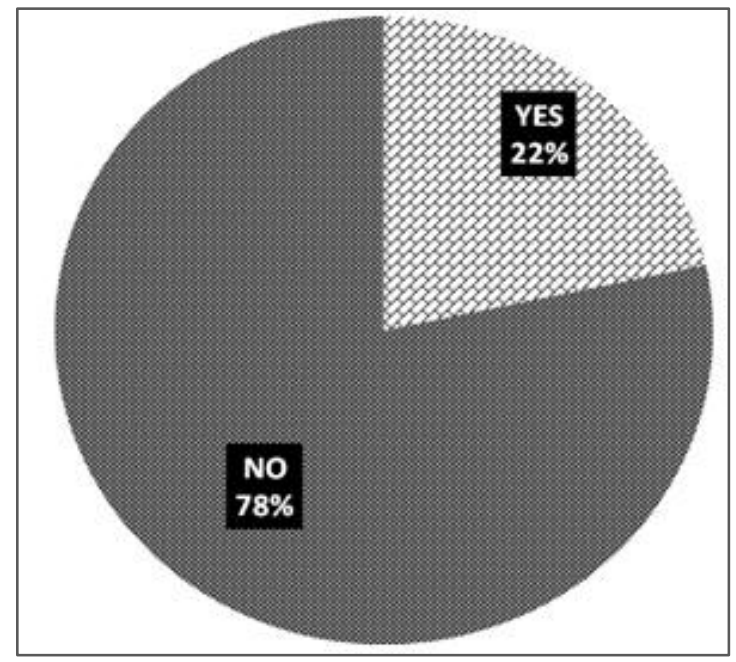

Fig 3:- Is it convenient to travel from your present location to any NMCN offices in Nigeria

\section{DISCUSSION}

\section{Nurses' attempt to communicate with NMCN}

Majority $91.1 \%$ of the respondents are Registered/Graduate nurses. This is in line with a study on communication barriers perceived by nurses and patients by Norouzinia et. al.,[11] where $92.7 \%$ of nurses held a degree in nursing. Ahmad et. al., [12] (2018) asserted that nurses who hold an academic degree utilises Information Communication Technology at ease than those who hold only a professional certificates. This is not similar with a study by Amoah et al., [13], where 69\% of the respondents had a Diploma in Nursing.

$74.1 \%$ of the respondents had tried to reach out to NMCN through email, phone calls, text messages, Letters and social media. This revealed that majority of the participants utilized Information Communication Technology in reaching out to NMCN. In a study by Bello et.al, [14], 95.9\% of the respondents utilised an active email address for communication and over half of the respondents $55 \%$ checked their e-mail on an average of three times on daily basis. $68 \%$ of the respondents predominantly use email as a means of Information Communication Technology for communication, followed by mobile phone communication which account for $65 \%$. In another study by Odiwuor [15], 27.6\% of the study participants utilized Information Communication Technology on their jobs. The study further stated that $64.8 \%$ of the respondents were provided with Desktops while $24.4 \%$ and $10.8 \%$ of the respondents had desktops/laptops and laptops respectively. The study is in contrast to a study by Niemi, Hupli \& Koivumen [16] where $5 \%$ of the respondents had quite poor Information Communication Technology skill. This means that the participants do not possess the technical know-how on the use of Information Communication Technology. In another study by Oyeboade \& Gbotosho [6], 67.3\% of the stated that they have phobia for the use of Information Communication Technology. It could be deduced that the fear associated with the use of Information Communication
Technology in this case may be due to inability to embrace change or inadequate knowledge on the use of ICT.

\section{Time-frame in NMCN reply of the messages}

$39.2 \%$ never got any reply when they reached out to NMCN via email. This is not in line with a study by Mutua [17] where $83 \%$ of the respondents disagreed that the use of ICT is a challenge confronting the Department of Extra Mural Studies. In a study by Lyngstad et al., [18], most of the respondents $94.9 \%$ who where nurses complained that electronic communication was an obstacle to communication due to different reason which were; Inefficient performance (31\%), System operation below expectation (31.1\%) and software problems (32.7\%). These variables could make a delay in the response to messages to be worsened as there is multi-causality on these themes of obstacle stated. The result of the present study is incongruence with the study by Wagner, Bezuidenhout \& Roos [19], where more than half of the respondents $(56.1 \%)$ stated that they were satisfied with the immediate response from the communication. It could be noted that a prompt feedback in communication enhances satisfaction of the public who the organisation is serving. In a study by Geraets [9], it was reported that health organisations are now in tune with the use of electronic means to bridging the gap in communication errors, delay or failure which were the factors to about $80 \%$ challenges of the health institution. The same study stated that most of the nurses (97\%) would utilize Information Communication Technology in four years to come. This trend utilization of ICT to enhancing communication is to allow room for easy transaction and effectiveness of the services to the public which the organisation serves.

\section{$>$ Access to NMCN offices for information}

Majority $78 \%$ stated that it is not convenient to travel from their location to any of the NMCN offices, even though $65.8 \%$ of the participants know that NMCN have zonal offices across the Six (6) geo-political zones in Nigeria. This corroborates the study by Mutua [17] where 93\% of the respondents agreed that distance was a challenge to communication in the department. In a study 
by Ahmad et al., [12] $65 \%$ of the participants had preference for accessing information through the modern technology than through the use of hard-copies. In the same study, $73 \%$ of the participants considered bringing the gap of distance by accessing information through the use of Information Communication Technologies. The present effort in saving time and cost of traveling in accessing services is now being made possible through the utilization of ICT. Modern technology could mitigate for the hardship of travelling distance to getting a problem solved. In another study by Odiwuor et. al., [15], more than half $58.28 \%$ of the participants had no access to Information Communication Technology. In a study by Lyngstad et al., [18], $97.2 \%$ of the respondents agreed that electronic communication is a veritable for interaction. In a study by Dash, Haller, Sommer et. al., [20], it was revealed that $85 \%$ of medical professionals utilise the internet and about $64 \%$ make use of email to communication. In the same study, it was stated that the use of electronic media has brought about increase in communication access with adequate functioning of delivery of services

\section{CONCLUSION}

The study concluded that most of the respondents who are graduate nurses had reached out to NMCN through different means among which the communication means were through emails and phone calls. Majority of the respondents stated that the geographical access to NMCN office is not easy for them even though most of them know that NMCN zonal offices exist in all the geopolitical zone of the country. Suggestion to improve communication by NMCN were stated as; Improved information Communication Technology, Personnel training and designation to man the electronic communication and active involvement of the NMCN personnel in positive projection of NMCN through effective communication to the people it is meant to serve.

\section{$>$ Implication for nursing management}

The study on Challenges in Communication with NMCN revealed that majority of the respondents who utilised ICT to reach out to NMCN are graduates. The implication of this to nursing management is that higher education for nursing could influence the use of modern technology as a mode of communication rather than the other system of communication like writing of letters in pen and paper. The respondents also noted that reaching the NMCN office from their domain is not easy; though they are aware there are zonal offices across the country. This implies that the present age of the $21^{\text {st }}$ century is geared towards making life convenient through the use of ICT in reaching out rather than travelling miles away to communicate and solve issues with NMCN. From the study, it is observed that the feedback in communication was noted to be poor; the implication is that it is expedient that service to be rendered should take cognisance of the present age strategies in its mode of communication.

\section{RECOMMENDATION}

Based on the results of the study the researchers hereby recommend that;

$>$ NMCN should create a 24 hour per week communication feedback system that will attend to nurses requesting for any form of information through any means from the NMCN.

$>$ NMCN should set up an active social media platforms (Twitter, Facebook, Instagram, WhatsApp) with hotlines (toll free) and employ internet savvy professionals who are fully trained in customer care and ready to respond to calls, mails and any request from nurses globally.

$>$ NMCN should have an active and effective email service with auto-response immediately and prosper response within 24 hours.

$>$ NMCN should make provision for self-service portal on her website to be interactive 24 hours with the use of bot (Artificial Intelligence apps) that can automatically return Frequently Asked Questions (FAQs).

$>\mathrm{NMCN}$ should continue to seek the support of the government and non-governmental organisation e.g SW Global, where need be, in a bid to improving communication network.

\section{REFERENCES}

[1]. Bucata,G \& Rizescu AM. The Role of Communication in Enhancing Work Effectiveness of an Organisation. Land Forces Academy Review. 2017); Vol. XXII, No 1 (85).

[2]. Fitzpatrick, L. The importance of communication and professional values relating to nursing practice. Links to Health and Social Care. 2018; Vol 3 (1).

[3]. Asamu FF. Impact of Communication on Workers' Performance in Selected Organisations in Lagos State, Nigeria. IOSR Journal Of Humanities And Social Science (IOSR-JHSS) 2014; Volume 19, Issue 8.

[4]. Robinson-Bassey GC \& Edet OB. Nursing Informatics Education and Use: Challenges and Prospects In Nigeria. Global Journal of Pure and Applied Sciences 2015; VOL. 21, 171-179. DOI: http://dx.doi.org/10.4314/gjpas.v21i2.9

[5]. Al-Azzawi, AKM \& Altmimi, LA. Effect of information and communication technology investment on the profitability of the Jordanian commercial banks. European Journal of Business and Management, 2015; 7(28): 166-73.

[6]. Oyeboade, JA \& Gbotosho, AS. "Availability, Access Points and Use Of Information and Communication Technologies By Science Students In Selected Private Secondary Schools In Ibadan, Oyo State, Nigeria" from http://digitalcommons.unl.edu/libphilprac/1595. 2017.

[7]. Filade, OA. Nursing and Midwifery Council of Nigeria commences online Registration for Newly Qualified and Post Basic nurses, 2018 retrieved fromhttps://www.nursingworldnigeria.com/2018/01/n ursing-and-midwifery-council-of-nursing- 
commences-online-registration-for-newly-qualiiedand-post-basic-nurses on 27/11/19.

[8]. Geraets A. How Hospitals are Using Smartphones to Raise HCAHPS Scores, 2019 retrieved from https://www.psqh.com/analysis/how-hospitals-areusing-smartphones-to-raise-hcahps-scores/ on 29/11/19.

[9]. Attenborough J \& Abbott, S. The impact of Nursing and Midwifery Council (NMC) revalidation on the professional identity of academic staff in a higher education institution: A qualitative study. Nursing Open, 2018; doi: 10.1002/nop2.224

[10]. Creative Research System, Sample size calculator, 2012; retrieved from http://www.surveysystem.com/sscalc.htm

[11]. Norouzinia R ,Aghabarari M,Shiri M, Karimi M \& Samami E . Communication Barriers Perceived by Nurses and Patients. Global Journal of Health Science. 2016; Vol. 8, No. 6.

[12]. Ahmad, M. M., Musallam, R., \& Allah, A. H. Nurses and internet health-related information: review on access and utility. Clujul medical (1957) 2018; 91(3), 266-273. doi:10.15386/cjmed-1024

[13]. Amoah VMK, Anokye R, Boakye DS \& Gyamfi N. Perceived barriers to effective therapeutic communication among nurses and patients at Kumasi South Hospital, Cogent Medicine, 2018; 5:1, DOI: 10.1080/2331205X.2018.1459341

[14]. Bello UL, Elshafie IF, Yunusa U, Ladan MA, Suberu A, Abdullahi SG \& Mba CJ. Utilization of Information Communication Technology among Undergraduate Nursing students in Tanta University, Egypt. Int J Nur Care. 2017; 1(3):1-8.

[15]. Odiwuor CW, Onyuka JHO \& Muhoho F et. al.,. Utilization of InformationCommunication Technology among Health care providers in Gatundu North District of Kiambu County, Kenya. International Journal of Applied Research 2015; 1(11): 1025-1029

[16]. Niemi A, Hupli M \& Koivumen M. The use of electronic communication for patient-professional interaction-nursing staff's point of view. FinJeHeW8(4); 2016

[17]. Mutua, AN. The Challenges Facing Effective Communication as a Public Relations Tool In Academic Institutions. (A Case Study of University of Nairobi - Department of Extra Mural Studies). 2014; A Research Project Is Submitted In Partial Fufilment of the Requirement For The Award Of Bachelor of Science In Communication And Public Relations in Moi University.

[18]. Lyngstad, M., Hofoss, D., Grimsmo, A., \& Helles $\emptyset$, R Predictors for assessing electronic messaging between nurses and general practitioners as a useful tool for communication in home health care services: a crosssectional study. Journal of medical Internet research, 2015; 17(2), e47. doi:10.2196/jmir.4056

[19]. Wagner JD, Bezuidenhout MC \& Roos JH. Communication satisfaction of professional nurses working inpublic hospitals Journal of Nursing Management 2015; 23,974-982.
[20]. Dash, J., Haller, D.M., Sommer, J. et al. Use of email, cell phone and text message between patients and primary-care physicians: cross-sectional study in a French-speaking part of Switzerland. BMC Health Serv Res 2016; 16, 549, doi:10.1186/s12913-0161776-9. 